\title{
KENYAMANAN SIRKULASI JALUR PEDESTRIAN DI JALAN AHMAD YANI SUKABUMI BERDASAR PERSEPSI PENGUNJUNG
}

\author{
Reza Prasetya ${ }^{1}$, Maria Immaculata Ririk Winandari ${ }^{2}$ \\ ${ }^{1}$ Program Magister Arsitektur, Universitas Trisakti, Jakarta \\ ${ }^{2}$ Jurusan Arsitektur, Universitas Trisakti, Jakarta \\ reza.sukabumi2807@gmail.com
}

\begin{abstract}
ABSTRAK
Pertumbuhan pusat kegiatan di sepanjang Jalan Ahmad Yani, Sukabumi sudah seharusnya diimbangi dengan peningkatan kualitas ruang terbuka di sepanjang koridor tersebut. Saat ini, terjadi penurunan kualitas ruang terbuka terutama di jalur pedestrian yang menyebabkan kenyamanan pengguna berkurang. Jalur pedestrian sebagai salah satu jalur sirkulasi seharusnya mengutamakan kenyamanan pergerakan pejalan kaki dari satu tempat ke tempat lain. Penelitian ini mengeksplorasi kenyamanan sirkulasi di koridor Jalan Ahmad Yani berdasar persepsi pengunjung. Metode penelitian menggunakan metode kuantitatif dengan skala Semantic Differential Method yang memiliki rentang 4 poin. Variabel penelitian terdiri dari dimensi jalur pedestrian, material jalur pedestrian, perlengkapan jalan, kebersihan, kemudahan pencapaian, serta dimensi pakir dan vegetasi. Responden terdiri dari 40 orang pengunjung yang melintas di koridor jalan tersebut. Hasil menunjukkan bahwa berdasar persepsi pengunjung, jalur pedestrian di koridor Jalan Ahmad Yani dianggap kurang nyaman untuk dimensi jalur pedestrian, material jalur pedestrian, perlengkapan jalan, kemudahan pencapaian, serta parkir motor dan vegetasi jalur pedestrian dan dianggap sangat kurang nyaman dalam hal kebersihan dan parkir mobil. Hal ini disebabkan penyempitan lebar jalur pedestrian karena penempatan barang dagangan dan pot tanaman, kurangnya jumlah tempat sampah dan tempat duduk di sepanjang koridor, serta ketiadaan halte untuk transportasi publik.
\end{abstract}

Kata Kunci: Kenyamanan, Sirkulasi, Jalur Pedestrian, Pengunjung, Jalan Ahmad Yani Sukabumi.

\section{ABSTRACT}

The growth of the activity centre along Jalan Ahmad Yani, Sukabumi is supposed to be offset by the increase of open space quality along the corridor. Currently, there is deterioration in the open space quality especially in the pedestrian way that causes reduced user comfort. The pedestrian way should prioritize the pedestrian movement comfort from one place to another. This research explores the convenience of circulation in the Jalan Ahmad Yani corridor based on visitor perception. The research method uses a quantitative method with a Semantic Differential Method scale that has range of 4 . The research variables consist of dimension and material of pedestrian way, street furniture, cleanliness, access, parking dimensions, as well as vegetation. Respondents consisted of 40 visitors who crossed the corridor. Results showed that based on visitors' perception, the pedestrian way in Jalan Ahmad Yani is considered less convenient for the dimension and material of pedestrian way, street furniture, access, motor parking, as well as Vegetation and very uncomfortable in terms of cleanliness and car parking. This 
is due to the narrowing the width of pedestrian way due to the merchandise and potted plants placement, and the lack of of bins and seats along the corridor as well as public transportation shelter.

Keywords: Comfort, Circulation, Pedestrian way, Visitors, Jalan Ahmad Yani Sukabumi.

\section{PENDAHULUAN}

Perkembangan Kota Sukabumi memiliki permasalahan kompleksitas sirkulasi yang semakin meningkat. Jacob (1961) telah lebih dulu menegaskan bahwa sebuah jalan tidak hanya butuh rasa aman, tetapi juga rasa nyaman untuk dipergunakan. Terkait pejalan kaki, keberadaan aktifitas berjalan kaki menciptakan jalur-jalur dan pola pergerakan di setiap sudut kota. Mehta (2008) menyatakan bahwa jalur pedestrian harus direncanakan dengan baik sesuai ketentuan dan standar aturan perencanaan karena salah satu kualitas hidup penduduk sebuah kota dipengaruhi oleh kualitas lingkungan jalur pejalan kaki. Semakin baik, aman dan nyaman lingkungan dan kualitas jalur pejalan kaki maka rasa memiliki penduduk kota akan semakin tinggi yang berpengaruh signifikan terhadap keseluruhan kepuasan serta kualitas hidup penduduk perkotaan.

Jalan Ahmad Yani merupakan salah satu koridor jalan penunjang kehidupan sosial dan ekonomi masyarakat Kota Sukabumi. Hal ini ditandai oleh mobilitas dan aktifitas yang cukup tinggi melalui variasi aktifitas di sepanjang koridor Jalan Ahmad Yani seperti perdagangan dan jasa, perkantoran, wisata, serta kegiatan sosial dan budaya. Peningkatan aktifitas ekonomi ditandai dengan munculnya aktifitas perdagangan di sepanjang koridor. Peningkatan aktifitas ekonomi di koridor Jalan Ahmad Yani tidak di imbangi dengan kenyamanan sirkulasi jalur pedestrian, seperti tidak adanya fasilitas pendukung, kualitas kondisi eksisting jalur pedestrian itu sendiri serta jalur pedestrian yang digunakan oleh para PKL (Pedagang Kaki Lima). Sanjaya dkk (2017) menyatakan bahwa jalur pedestrian tidak berfungsi secara maksimal untuk pejalan kaki karena dipengaruhi oleh faktor fungsi, mobilitas, fasilitas, aksesibilitas, keamanan, kebersihan, dan keindahan yang menurun. Hal ini mengakibatkan adanya perbedaan antara persepsi pengguna dengan harapan mereka terhadap kondisi eksisting jalur pedestrian koridor Jalan Ahmad Yani Kota Sukabumi.

Penelitian ini bertujuan untuk mengetahui persepsi pengunjung terhadap kenyamanan sirkulasi jalur pedestrian di koridor Jalan Ahmad Yani Kota Sukabumi. Lingkup penelitian meliputi kondisi fisik dan jalur pedestrian serta persepsi pengunjung terhadap kenyamanan jalur tersebut.

\section{TINJAUAN PUSTAKA}

Kenyamanan Sirkulasi Jalur Pedestrian

Zakaria dan Ujang (2015) mengungkapkan bahwa kenyamanan pedestrian sangat dipengaruhi oleh kualitas lingkungan yang menyenangkan untuk mereka berjalan. Kenyamanan tersebut sangat dipengaruhi antara lain oleh kebersihan, dimensi ruang, perlengkapan jalan, akses, material, parkir, dan vegetasi (Zakaria dan Ujang, 2015; Nasrudin dkk, 2018; Dewi dan Rakhmatollah, 2018; Wahyudi dan Abidin, 2018). 
Nasrudin dkk (2018) mengungkapkan bahwa pemeliharaan kebersihan di sepanjang jalur pedestrian akan meningkatkan kenyamanan pengguna. Jarak antar tempat sampah disarankan setiap 20 meter (Tegar dkk, 2018).

Terkait dengan dimensi jalur pedestrian, Harris dan Dines (1988) menjabarkan kebutuhan ruang personal antar pejalan kaki dengan jarak sekitar 1,8m untuk kegiatan publik dan 2,8m hingga 3,6m untuk kegiatan perbelanjaan. Tinggi jalur pedestrian disarankan tidak lebih dari $15 \mathrm{~cm}$ agar dapat di akses oleh semua orang (ITDP Indonesia, 2019). Hal ini dilakukan agar kendaraan tidak masuk dan menggunakan jalur pedestrian.

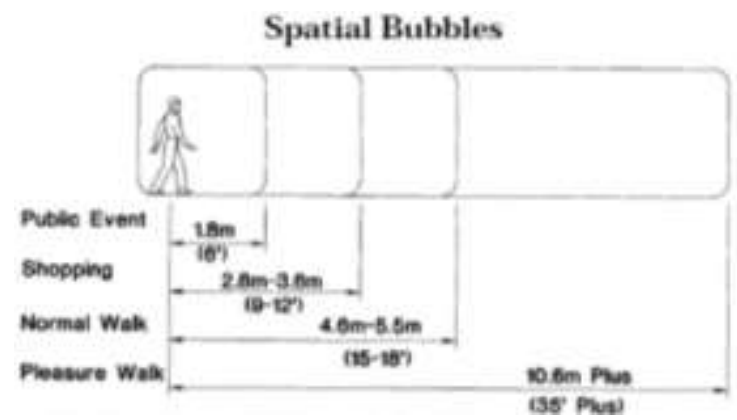

\section{Gambar 1. Jarak personal antar pejalan kaki Sumber: Harris dan Dines, 1988}

Merujuk Harris dan Dines (1988), perlengkapan jalan digunakan untuk kenyamanan pengguna jalan. Elemen perlengkapan tersebut antara lain terdiri dari lampu jalan, halte, papan reklame/ informasi, dan tempat duduk. Sifat penerangan untuk jalur pedestrian sebaiknya tidak seragam dengan distribusi pencahayaan sekitar $2 \mathrm{~m}$ agar penglihatan ke arah pejalan kaki lain tetap jelas dan jarak antara lampu sekitar 10m (Harris dan Dines, 1988). Ketinggian lampu sekitar 1m-1.5m (Mamuaja dkk, 2018). Penempatan halte dapat dilakukan di atas trotoar atau bahu jalan dengan jarak minimal $1 \mathrm{~m}$ dari tepi jalur lalu lintas, memiliki lebar minimal $2 \mathrm{~m}$, panjang $4 \mathrm{~m}$, dengan tinggi atap paling bawah minimal $2,5 \mathrm{~m}$ dari lantai (Harris dan Dines, 1988). Jarak antara halte adalah $300 \mathrm{~m}$ (Harris dan Dines, 1988). Halte dan jalur pedestrian sebaiknya berpenutup atap untuk melindungi pejalan kaki dari hujan dan panas (Nasrudin dkk, 2018). Mengenai papan reklame/informasi, Harris dan Dinnes (1988) menyatakan bahwa perletakan papan informasi sebaiknya dalam jarak tangkap setinggi mata sekitar 1,4m-1,8m dalam kondisi berdiri dan $1 \mathrm{~m}-1,2 \mathrm{~m}$ dalam kondisi duduk. Pemilihan dan peletakan elemen tempat duduk harus disesuaikan dengan elemen lainnya agar menyatu dengan lingkungan sekitarnya dengan jarak antara tempat duduk sekitar 10m (Harris dan Dinnes, 1988).

Terkait kemudahan pencapaian, Tanan (2011) mengungkapkan bahwa jarak tempuh orang berjalan kaki di Indonesia sekitar 300m-400m. Lebih detil, Indraswara (2007) menyatakan 
bahwa jarak nyaman untuk berbelanja membawa barang sekitar 300m. Dari sisi material, permukaan jalur pedestrian yang biasa digunakan menurut Kodariyah (2004) adalah batu, cetakan beton (Paving) dan batu kerikil. Setiap bahan-bahan ini mempunyai karakter yang membuatnya sesuai untuk suatu situasi. Hampir semua batu dengan bagian atas datar, dapat digunakan untuk perkerasan jalur pedestrian.

Terkait parkir, jalur pedestrian yang menjadi tempat parkir menyulitkan sirkulasi pejalan kaki (Wahyudi dan Abidin, 2018). Merujuk Miro (1997), penempatan parkir di sepanjang jalan dapat dilakukan di badan jalan atau di luar badan jalan.
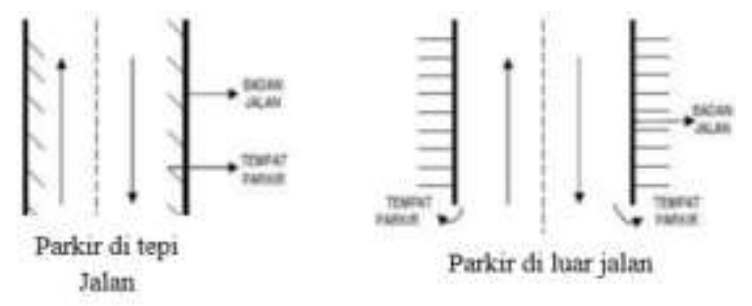

Gambar 2. Model-Model Pola Parkir

Sumber : Miro, 1997

Terkait vegetasi, pohon rindang sangat baik digunakan untuk pelindung pejalan kaki dari panas dan hujan (Nasrudin dkk, 2018). Tujuan dari penanaman vegetasi tepi jalan adalah untuk memisahkan pejalan kaki dari jalan raya dengan alasan keselamatan dan kenyamanan (Lynch, 1981). Merujuk Arnold (1980), ketinggian percabangan pohon yang nyaman untuk berjalan berkisar 2,4m-4,5m sedangkan untuk pergerakan kendaraan minimal 4,5m.

\section{Persepsi Pejalan Kaki}

Persepsi adalah suatu gambaran, pengertian serta interpretasi seseorang mengenai suatu objek, terutama bagaimana orang tersebut menghubungkan informasi ini dengan dirinya dan lingkungan dimana ia berada (Porteous, 1977). Menurut Brockman dan Merriem (1973), faktor-faktor yang mempengaruhi persepsi adalah jenis kelamin dan umur, latar belakang kebudayaan, pendidikan, pekerjaan, asal/ tempat tinggal, status ekonomi, waktu luang, dan kemampuan fisik serta intelektual.

\section{METODOLOGI}

Metode penelitian yang digunakan adalah metode kuantitatif melalui deskriptif analisis, dengan cara survey lapangan, studi dokumentasi/pustaka, kuesiner dan wawancara (Hidayat, 2011). Pengumpulan data dilakukan melalui pengamatan langsung, wawancara dengan menggunakan kuesioner, dan studi pustaka. Data fisik terdiri atas dimensi jalur pedestrian, material jalur pedestrian, kebersihan, perlengkapan jalan, kemudahan pencapaian, dimensi pakir kendaraan dan vegetasi jalur pedestrian. Data persepsi diperoleh dengan cara membagikan kuesioner mengenai kondisi eksisting kenyamanan sirkulasi dalam jalur pedestrian. Responden terdiri dari 40 orang responden yang berpotensi menggunakan jalur pedestrian. 
Pengolahan data mengenai persepsi menggunakan skala Semantic Differential Method dengan skala 4 nilai. Nilai 1 menunjukan sangat kurang, nilai 2 menunjukan kurang, nilai 3 menunjukan baik, dan nilai 4 menunjukan sangat baik. Hasil olah data tersebut kemudian dicari persentasenya untuk selanjutnya dideskripsikan berdasarkan rentang kriteria kenyamanan.

Tabel 1. Pembagian kategori tingkat kenyamanan sirkulasi \& cara perhitungan

\begin{tabular}{|c|c|}
\hline $\begin{array}{c}\text { Kategori Tingkat } \\
\text { Kenyamanan Sirkulasi }\end{array}$ & Persentase $\%$ \\
\hline Sangat Baik (4) & 81,25 s.d 100 \\
\hline Baik (3) & 62,5 s.d 81,24 \\
\hline Kurang (2) & 43,75 s.d 62,4 \\
\hline Sangat Kurang (1) & 25 s.d 43,74 \\
\hline
\end{tabular}

\section{HASIL \& PEMBAHASAN}

Jalan Ahmad Yani berada di pusat Kota Sukabumi dengan panjang sekitar 903m. Jalan ini di kelilingi oleh Balai Kota Sukabumi di bagian Utara, Rumah Sakit Ridogalih serta Jazz Hotel di sisi Timur, alun-alun Kota Sukabumi dan Pendopo Bupati di sisi Barat, serta Pasar Pelita dan Stasiun Kereta Api Sukabumi di sisi Selatan.

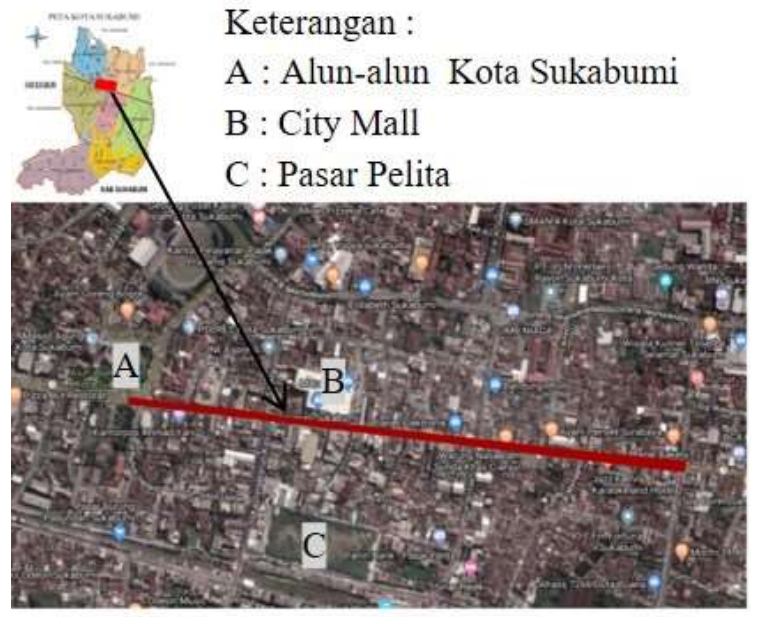

Gambar 3. Peta Lokasi Penelitian

Koridor jalur pedestrian jalan Ahmad Yani terhubung ke banyak jalan, sehingga dengan mudah di akses oleh masyarakat. Baik yang menggunakan kendaraan pribadi maupun angkutan umum. Koridor Jalur pedestrian jalan Ahmad Yani ini merupakan jalur pedestrian 
dengan berbagai macam aktivitas didalamnya seperti perbankan, perkantoran, pusat perbelanjaan, pertokoan, tempat makan \& pasar. Oleh sebab itu koridor Jalan Ahmad Yani di klasifikasikan sebagai jalur pedestrian komersial yang selalu ramai dikujungi. Alun-alun Kota Sukabumi yang berada di sisi barat yang menjadikannya sebagai taman wisata atau tempat bersantai, biasanya mulai ramai pengunjung sekitar pukul 16.00 WIB sampai larut malam.

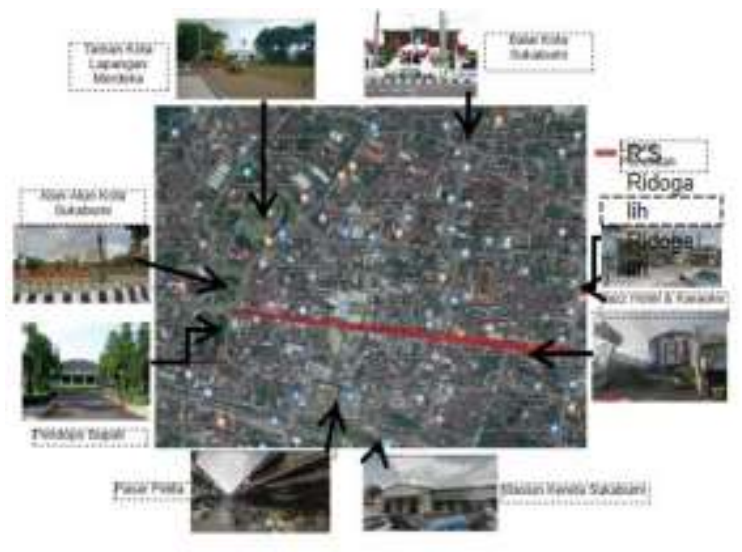

Gambar 4. Kondisi Eksisting Lokasi Penelitian

Aktifitas jalur pedestrian di sepanjang Jalan Ahmad Yani sangat beragam. Keragaman tersebut antara lain terdiri dari kegiatan melintas oleh pejalan kaki itu maupun berdagang. Responden penelitian adalah pengunjung jalur pedestrian dengan karakteristik yang beragam dari sisi jenis kelamin, usia, Pendidikan, dan pekerjaan. Karakteristik responden dari sisi jenis kelamin terdiri dari 20 orang perempuan dan 20 orang laki-laki. Usia kurang dari 20 tahun sebanyak 12 orang, usia 20 hingga 30 tahun sebanyak 18 orang, usia 30 hingga 40 tahun sebanyak 5 orang, dan usia 40 hingga 50 tahun sebanyak 5 orang. Dari sisi pendidikan, 1 orang responden tidak sekolah, 2 orang berpendidikan SMP/Tsanawiyah, 18 orang SMA/Aliyah/SMK, 6 orang Diploma, dan 14 orang S1. Responden yang tidak bekerja sejumlah 3 orang, pelajar/ mahasiswa sejumlah 14 orang, karyawan swasta sejumlah 18 orang, dan wiraswasta sejumlah 5 orang. Karakteristik tersebut disajikan dalam tabel berikut.

Tabel 2. Karakteristik Responden

\begin{tabular}{lll}
\hline No & \multicolumn{1}{c}{ Variabel } & \multicolumn{1}{c}{ Kategori } \\
\hline $\mathbf{1}$ & Jenis & Laki - Laki : 20 Orang \\
& Kelamin & Perempuan : 20 Orang \\
\hline $\mathbf{2}$ & Usia & <20 Tahun : 12 Orang \\
& & 20-30 Tahun : 18 Orang \\
& & 30-40 Tahun : 5 Orang \\
& & 40-50 Tahun : 5 Orang \\
\hline $\mathbf{3}$ & Pendidikan & Tidak Sekolah : 1 Orang \\
\hline
\end{tabular}




\begin{tabular}{ll}
\hline & SMP/Tsanawiyah : 2 Orang \\
& SMA/SMK/Aliyah : 18 Orang \\
& Akademik/D3 : 6 Orang \\
& S1 : 14 Orang \\
\hline $4 \quad$ Pekerjaan & Tidak Bekerja : 3 Orang \\
& Pelajar/Mahasiswa : 14 Orang \\
& Karyawan Swasta : 18 Orang \\
& Wiraswasta : 5 Orang \\
\hline
\end{tabular}

Temuan penelitian menunjukkan bahwa pengunjung menganggap kondisi jalur pedestrian di sepanjang koridor jalan tersebut kurang nyaman di hampir semua kriteria bahkan ada kriteria yang dianggap sangat kurang nyaman. Elemen yang dianggap kurang nyaman meliputi dimensi jalur pedestrian, perlengkapan jalan, kemudahaan pencapaian (dari halte/ kendaraan umum ke tujuan), material permukaan jalur pedestrian, parkir motor, dan vegetasi. Elemen yang dianggap sangat kurang nyaman adalah kebersihan dan parkir mobil. Pengunjung menganggap perlu dilakukan peningkatan kondisi jalur pedestrian menjadi agar mereka lebih memilih berjalan kaki di koridor tersebut dibandingkan dengan menggunakan kendaraan bermotor.

Kebersihan di sepanjang koridor Jalan Ahmad Yani dianggap kurang nyaman bahkan beberpa responden menganggap sangat kurang nyaman. Ketidaknyamanan tersebut disebabkan adanya tumpukan sampah di beberapa tempat. Tempat sampah hanya ditemukan di beberapa titik di sepanjang koridor jalan sehingga mengakibatkan sampah berserakan di jalur pedestrian maupun jalur kendaraan (lihat Gambar 5). Hal ini memperkuat pernyataan Tegar dkk (2018) bahwa jarak antar tempat sampah yang baik sekitar $20 \mathrm{~m}$ untuk mempermudah sistem pengumpulan dan pengangkutan sampah. Jalur pedestrian yang bersih akan menambah daya tarik serta kenyamanan individu saat berjalan.

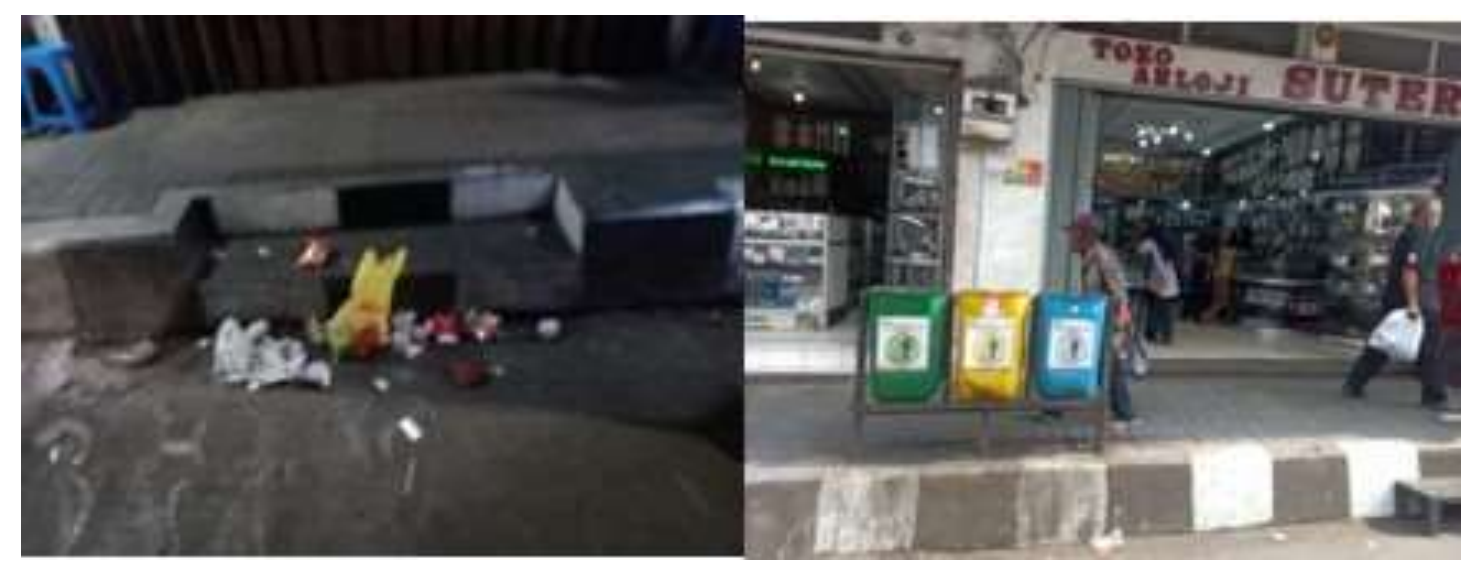

Gambar 5. Kondisi kebersihan

Dimensi jalur pedestrian dianggap kurang nyaman oleh pengunjung. Hal ini disebabkan oleh lebar jalur yang tidak sesuai standar serta penggunaan sebagian jalur pedestrian untuk 
penempatan barang pedagang kaki lima sehingga lebar jalur pedestrian menyempit. Dimensi jalur pedestrian di area shopping, menurut Harris dan Dines (1988) adalah 2,8m hingga 3,6m sedangkan lebar jalur pedestrian di Jalan Ahmad Yani 1,2 m (lihat Gambar 6).

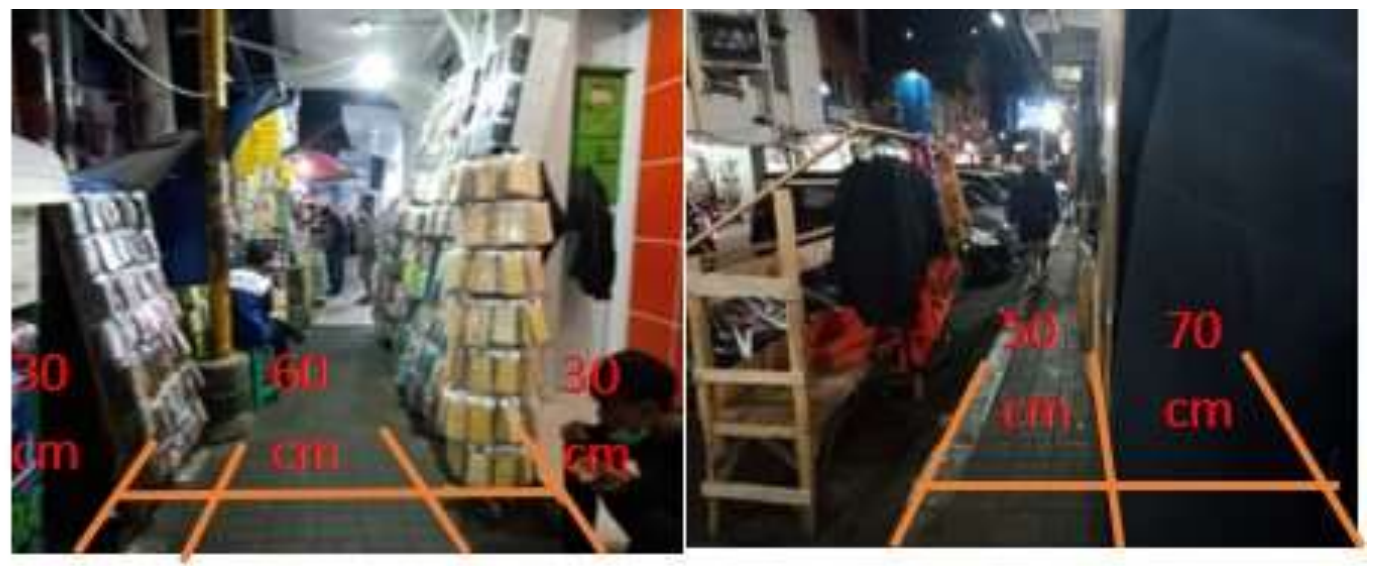

Gambar 6. Kondisi jalur pedestrian

Kelengkapan perlengkapan jalan dianggap kurang nyaman oleh pengunjung karena hanya ada lampu jalan dan papan informasi/rambu-rambu lalu lintas saja (lihat Gambar 7). Kondisi ini mempertegas pernyataan Harris dan Dines (1988) bahwa kelengkapan dan perlengkapan jalan secara kolektif dan menarik dapat meningkatkan kenyamanan, kesenangan, informasi, kontrol sirkulasi dan perlindungan bagi pengguna jalan.
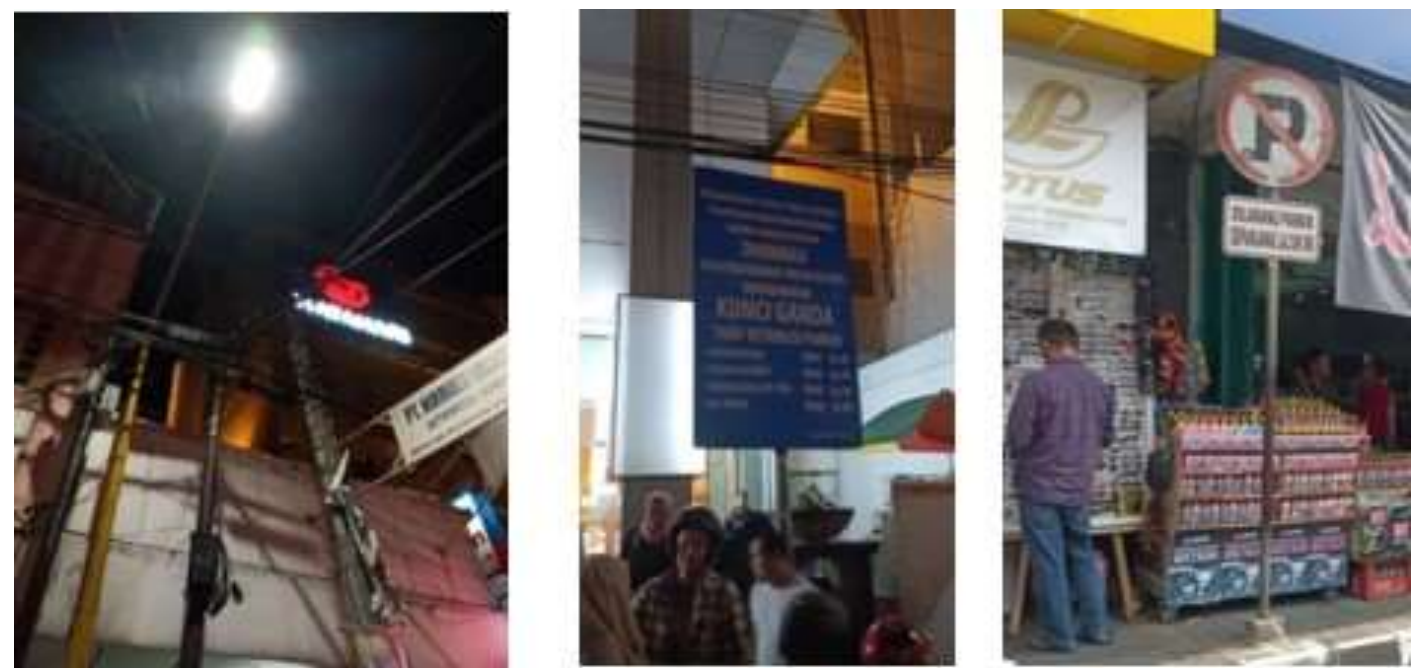

Gambar 7. Kondisi perangkat jalan

Kemudahan pencapaian dianggap kurang nyaman oleh pengunjung karena tidak adanya fasilitas halte untuk menunggu walaupun banyak akses transportasi publik (lihat Gambar 8). Hal ini tidak sesuai dengan pernyataan Untermann (1984) bahwa kemudahan moda transportasi umum sebagai moda penghantar sebelum atau sesudah berjalan kaki sangat 
mempengaruhi jarak tempuh orang berjalan kaki. Di jalan Ahmad Yani, ketersediaan perangkat jalan berupa halte dengan penempatan yang merata di sepanjang koridor sangat mempengaruhi jarak tempuh orang berjalan.

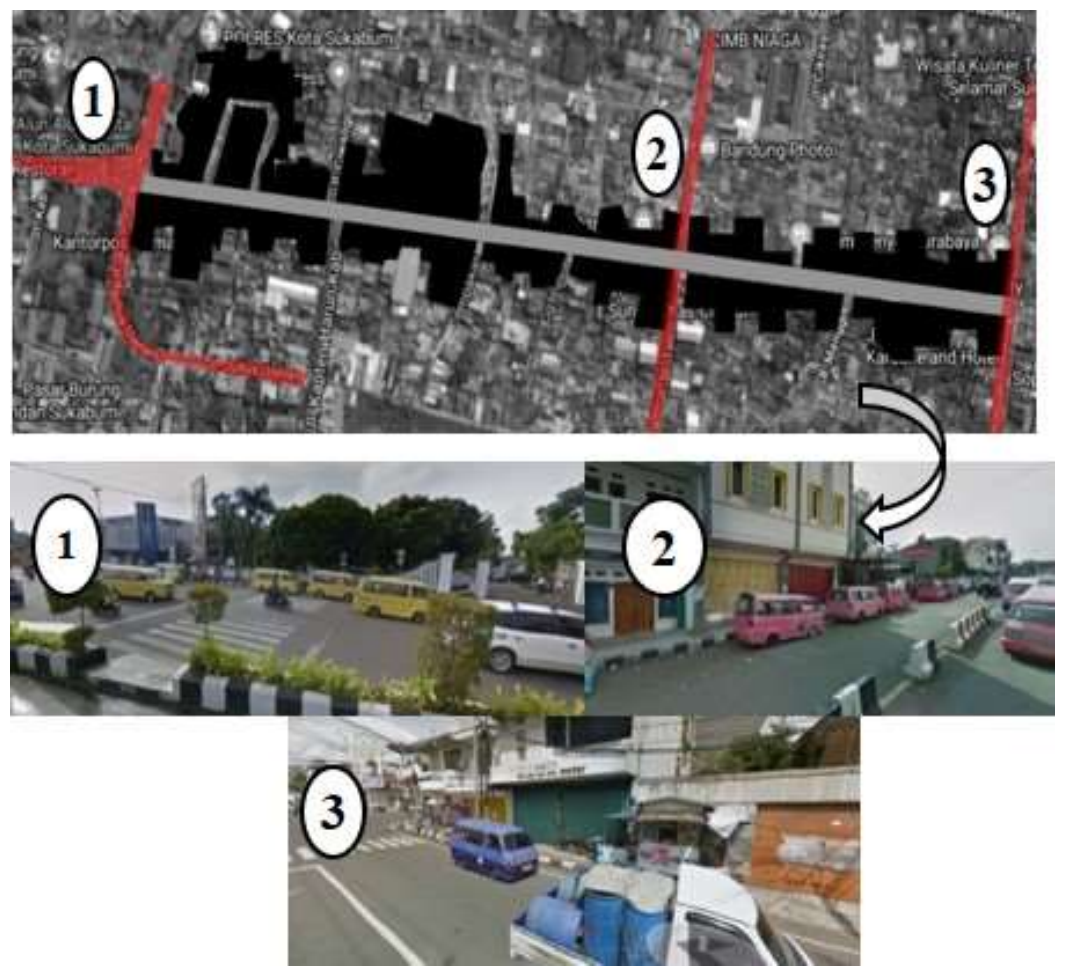

Gambar 8. Akses transportasi publik

Material permukaan jalur pedestrian dianggap kurang nyaman oleh pengunjung. Penggunaan material dengan permukaan tidak licin yang sesuai dengan pernyataan Kodariyah (2004) berupa cetakan beton/paving ternyata masih dianggap kurang nyaman karena kondisi material yang kurang terawat (lihat Gambar 9). Kondisi yang kurang terawatt menyebabkan permukaan jalur pedestrian menjadi licin terlebih di saat hujan.

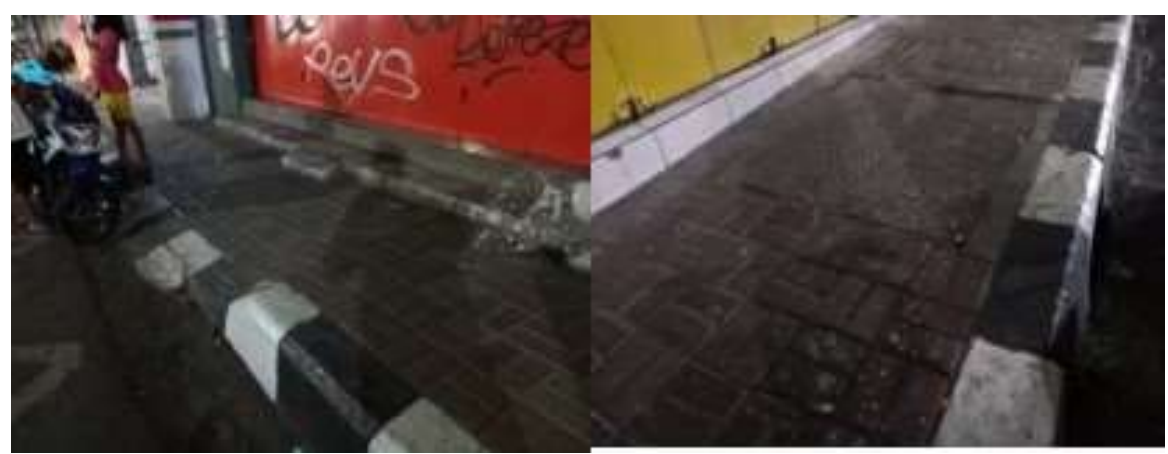

Gambar 9. Material jalur pedestrian 
Kondisi parkir kendaraan motor dianggap kurang nyaman sedangkan parkir mobil dianggap sangat kurang nyaman. Hal ini disebabkan karena parkir yang mengambil sebagian jalur pedestrian (lihat Gambar 10). Hal ini mempertegas pernyataan Wahyudi dan Abidin (2018) tentang sulitnya sirkulasi pejalan kaki jika jalur pedestrian menjadi tempat parkir. Pakir kendaraan di koridor Jalan Ahmad Yani memakai sistem parkir di luar badan jalan yaitu parkir yang lokasi penempatan kendaraannya tidak berada di badan jalan. Jumlah kendaraan yang parkir di koridor tersebut sudah melampaui kapasitas parkir sehingga selalu menimbulkan kemacetan di sepanjang koridor jalan ahmad yani. Keselamatan pejalan kaki yang berjalan di bahu jalan sangat beresiko terhadap kemungkinan kecelakaan. Seharusnya parkir kendaraan dibuat satu lokasi/gedung khusus parkir sehingga bahu jalan bisa digunakan untuk pelebaran jalur pedestrian.
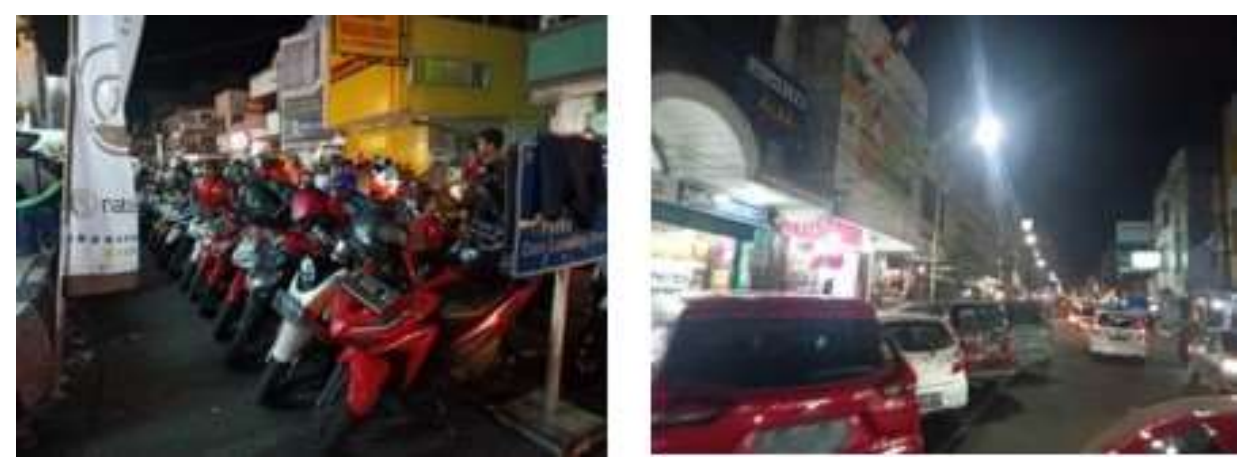

Gambar 10. Parkir kendaraan

Vegetasi jalur pedestrian dianggap sangat kurang nyaman karena pohon, tanaman, dan elemen vegetasi lainnya tidak tertata dengan baik (lihat Gambar 11). Penempatan tanaman di dalam pot, mengurangi ruang pejalan kaki yang seharusnya tanaman tersebut memiliki ruang tersendiri sehingga mempengaruhi kenyamanan sirkulasi jalur pedestrian. Penambahan pohon, tanaman, atau elemen vegetasi lainnya pada jalur pedestrian kaki tidak hanya berfungsi meciptakan rasa nyaman, tetapi juga bermanfaat untuk menciptakaan suasana yang menyenangkan dan sebagai peneduh di jalur pedestrian.

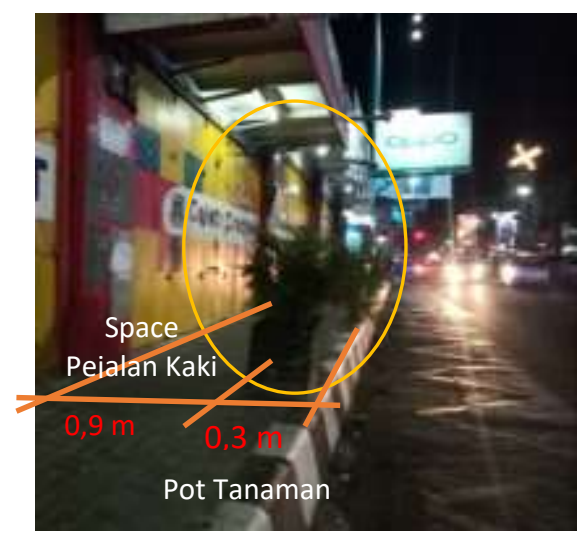

Gambar 11. Vegetasi di Jalan Ahmad Yani 
Berdasarkan uraian di atas, terdapat 2 variabel yang dianggap sangat kurang nyaman oleh pengunjung yaitu kebersihan dan parkir mobil sedangkan 6 variabel lainnya dianggap kurang nyaman. Kedelapan variabel kenyamanan sirkulasi berdasarkan persepsi pengunjung di sepanjang koridor jalur pedestrian di Jalan Ahmad Yani, Sukabumi dapat dilihat pada Tabel 3 berikut ini.

Tabel 3. Persepsi pengunjung terhadap kenyamanan jalur pedestrian

\begin{tabular}{|c|c|c|c|c|}
\hline Aspek & Skor & $\begin{array}{c}\% \% \\
\text { Penilai } \\
\text { an } \\
\end{array}$ & $\begin{array}{l}\text { Kategori } \\
\text { Kenya- } \\
\text { manan }\end{array}$ & Keterangan \\
\hline Kebersihan & 70 & 43,75 & $\begin{array}{l}\text { Sangat } \\
\text { Kurang }\end{array}$ & $\begin{array}{l}\text { Banyak sampah, } \\
\text { tempat sampah kurang }\end{array}$ \\
\hline $\begin{array}{l}\text { Dimensi jalur } \\
\text { pedestrian }\end{array}$ & 77 & 48,125 & Kurang & $\begin{array}{l}\text { Sebagian ruang dipakai } \\
\text { barang pedagang }\end{array}$ \\
\hline Perleng-kapan jalan & 77 & 48,125 & Kurang & $\begin{array}{l}\text { Hanya ada lampu } \\
\text { penerangan }\end{array}$ \\
\hline $\begin{array}{c}\text { Kemudahan } \\
\text { pencapaian (dari } \\
\text { halte/ kendaraan } \\
\text { umum) } \\
\end{array}$ & 81 & 50,625 & Kurang & Tidak ada halte \\
\hline $\begin{array}{l}\text { Material permukaan } \\
\text { jalur pedestrian }\end{array}$ & 95 & 59,375 & Kurang & $\begin{array}{c}\text { Kondisi material } \\
\text { permukaan tidak } \\
\text { terawat }\end{array}$ \\
\hline Parkir mobil & 68 & 42,5 & $\begin{array}{l}\text { Sangat } \\
\text { Kurang }\end{array}$ & $\begin{array}{c}\text { Parkiran mobil kurang } \\
\text { banyak }\end{array}$ \\
\hline Parkir motor & 72 & 45 & Kurang & $\begin{array}{l}\text { Parkir motor di bahu } \\
\text { jalan }\end{array}$ \\
\hline Vegetasi & 72 & 45 & Kurang & Tanaman sedikit \\
\hline
\end{tabular}

\section{SIMPULAN}

Penelitian terhadap 40 orang pengunjung yang melintas di Jalan Ahmad Yani di Kota Sukabumi ini mengungkapkan adanya ketidaknyamanan pengunjung terhadap sirkulasi di jalur pedestrian. Pengunjung mengelompokkan kategori ketidaknyamanan ke dalam 2 kelompok yaitu kurang nyaman dan sangat kurang nyaman. Kelompok yang diganggap kurang nyaman adalah dimensi jalur pedestrian, material jalur pedestrian, perlengkapan jalan, kemudahan pencapaian, pakir motor dan vegetasi jalur pedestrian. Kelompok yang dianggap sangat kurang nyaman adalah kebersihan dan parkir mobil. Kondisi ini disebabkan karena kekurangan jumlah tempat sampah dan tempat duduk di sepanjang koridor, penyempitan jalur pedestrian karena penempatan barang dagangan dan pot tanaman, serta ketiadaan halte di jalur transportasi publik. Peningkatan kondisi jalur 
pedestrian sangat diperlukan agar pengunjung lebih memilih berjalan kaki yang sehat dan ramah lingkungan serta mengurangi penggunaan kendaraan bermotor.

\section{DAFTAR RUJUKAN}

Arnold, HF. 1980. Trees in Urban Design. New York: Van Nostrand Reinhold Co

Brockman CF, Merriem LC. 1973. Recreational Use of Wild Land. New York: Mc. Graw- Hill Book Inc. Co.

Dewi, Diah Intan Kusumo; Rakhmatulloh, Anita Ratnasari. 2018. Connectivity between Pedestrian Ways and Bus Rapid Transit Shelter in Banyumanik and Pedurungan, Semarang. Jurnal Teknik. Sipil \& Perencanaan. 20(2). p. 56 - 64

Harris CW, Dines NT. 1988. Time Saver Standards for Landscape Architecture: Design and Construction Data. Mc. Graw-Hill Book Inc. Co. New York.

Hidayat, Sedarmayanti., 2011. Metodologi Penelitian. Bandung: cv. Mandar Maju.

Indraswara, M Sahid. 2007. Kajian Kenyamanan Jalur Pedestrian Pada Jalan Imam Barjo Semarang. Enclosure. 6(2). p. 59-69

ITDP Indonesia. 2019. Pandungan Desain Fasilitas Pejalan Kaki: DKI Jakarta 2017-2022. Jakarta: Institute for Transportation Development Policy Indonesia

Jacobs, Jane. 1961. The Use of Sidewalks: Safety. The Death and Life of Great American Cities. New York: Vintage. p. 106-111

Kodariyah, R. 2004. Jalur Pejalan Kaki di Kawasan Perdagangan di Kota Bogor. Bogor: Institut Pertanian Bogor

Lynch, Kevin. 1981. a Theory of Good City Form. MIT Press

Mamuaja, Denny Maxim Abraham; Rompis, Semuel JR; Timboeleng, James A. 2018. Analisa Tingkat Kenyamanan Pejalan Kaki Di Kota Tomohon. Jurnal Ilmiah Media Engineering. 8(2). p. 1132-1143

Mehta. V, 2008. Walkable streets: pedestrian behavior, perceptions and attitudes. Journal of Urbanism: International Research on Place making and Urban Sustainability, Vol. 1, Issue 3, 2008, pp. 217-245. doi:10.1080/17549170802529480

Miro, Fidel. 1997. Sistem Transportasi Kota. Bandung: Penerbit Tarsito.

Nasrudin, Na'asah; Sarimin, Muna; Ibrahim, Norhayati. 2018. Assessing a Walkable Environment in Jalan Tuanku Abdul Rahman, Kuala Lumpur, Malaysia. Planning Malaysia: Journal of the Malaysian Institute of Planners. 16(3). pp. 261 - 27

Porteous, JD. 1977. Environment and Behavior: Planning and Everyday Urban Life. Massachusetts: Addison-Wesley Pub Inc.Co.

Sanjaya, Riyan; Soedarsono; Mudiyono, Rachmat. 2017. Analisis Fungsi Dan Kenyamanan Jalur Pedestrian Kawasan Di Kota Pangkalan Bun Studi Kasus: Bundaran Pancasila. Prosiding Seminar Nasional Inovasi dalam Pengembangan Smart City. 1(1). pp. 108122

Tanan, Natalia. 2011. Fasilitas Pejalan Kaki. Bandung: Puslitbang

Tegar; Ginting, Nurlisa; Suwantoro, H. 2018. How to Improve the Comfort of Kesawan Heritage Corridor, Medan City. IOP Conf. Series: Earth and Environmental Science 126 (2018) 012204 doi:10.1088/1755-1315/126/1/012204 
Untermann, Richard, 1984. Accommodating the Pedestrian: Adapting Towns and Neighborhoods for Walking and Bicycling. New York: Van Nostrand Reinhold Co

Wahyudi, Eko; Abidin, Zainal. 2018. Pengaruh Pedagang Kaki Lima Terhadap Penanggulangan Bahaya Kebakaran Pada Jl. Hayam Wuruk Kota Semarang. PROKONS: Jurnal Teknik Sipil. 11(2). p. 64-68

Zakaria, Juriah; Ujang, Norsidah. 2015. Comfort of Walking in the City Center of Kuala Lumpur. Procedia - Social and Behavioral Sciences 170 (2015) 642-652. doi: 10.1016/j.sbspro.2015.01.066 